ORIGINAL ARTICLE / ARTIGO ORIGINAL

\title{
Comparison between self-reported sleep duration and actigraphy among adolescents: gender differences
}

\author{
Comparação entre duração do sono autodeclarada e \\ actigrafia entre adolescentes: diferenças de gênero \\ Luciane Gaspar Guedes', Gabriela de Azevedo Abreu", Daniel Frossard Rodrigues', \\ Liliane Reis Teixeira"', Ronir Raggio Luiz", Katia Vergetti Bloch"
}

\begin{abstract}
Introduction: There are only few agreement studies between subjective measures of sleep and actigraphy among adolescents. Objective: To compare self-reported sleep and actigraphy in this age group, by studying gender differences and, using a new graphical approach, the survival agreement plot. Methods: Thirty-seven subjects, aged 12 to 17 years, answered questions about nocturnal sleep duration and used actigraphy for seven days. The mean and median differences between the informed sleep and the recorded one, the intraclass correlation coefficient, the Bland-Altman plot and the survival-agreement plot were used. Results: A mean difference of about one hour $(\mathrm{SD}=2.1$; median $=0.5 ; \mathrm{p}<0.01)$ was found between both strategies, which was higher among boys, 1.9 hours $(\mathrm{SD}=2.8$; median $=1.6 ; \mathrm{p}<0.05)$, than among girls, 0.5 hours $(\mathrm{SD}=1.4$; median $=0.3 ; \mathrm{p}=0.11$ ). The graphical evaluation showed similar results, as well as the intraclass correlation coefficient: $0.06(95 \% \mathrm{CI}=-0.33-0.46 ; \mathrm{p}=0.489)$ for boys and $0.43(95 \% \mathrm{CI}=0.12-0.83$; $\mathrm{p}<0.001$ ) for girls. Conclusions: Our data are consistent with previous studies as to non-agreement between the two methods. These results are relevant because this is the first study of concordance between subjective measures of sleep and actigraphy among Brazilian adolescents, as far as we know. In addition, they reinforce the need of a careful use of nocturnal sleep measures among adolescents, mainly among boys.
\end{abstract}

Keywords: Sleep. Questionnaires. Actigraphy. Adolescents. Gender. Brazil.

I'nstituto de Puericultura e Pediatria Martagão Gesteira, Universidade Federal do Rio de Janeiro - Rio de Janeiro (RJ), Brazil.

"Instituto de Estudos em Saúde Coletiva, Universidade Federal do Rio de Janeiro - Rio de Janeiro (RJ), Brazil.

"'Escola Nacional de Saúde Pública, Fundação Oswaldo Cruz - Rio de Janeiro (RJ), Brazil.

Corresponding author: Luciane Gaspar Guedes. Rua Bruno Lobo, 50, Cidade Universitária, CEP: 21941-912, Rio de Janeiro, RJ, Brazil. E-mail: lugaspar09@yahoo.com.br

Conflict of interests: nothing to declare - Financial support: MCT/FINEP/MS/SCTIE/DECIT - CT/SAÚDE. 
RESUMO: Introdução: Existem poucos estudos de concordância entre as medidas subjetivas de sono e a actigrafia entre adolescentes. Objetivo: Comparar o sono autodeclarado e a actigrafia neste grupo etário, estudando as diferenças quanto ao sexo e, usando uma nova abordagem gráfica, o gráfico de concordância e sobrevivência. Métodos: Trinta e sete indivíduos de 12 a 17 anos responderam a questões sobre a duração do sono noturno e usaram actigrafia por sete dias. As diferenças entre as médias e as medianas entre sono informado e a medida objetiva, o coeficiente de correlação intraclasse e os gráficos de Bland-Altman e de concordância e sobrevivência foram aplicados. Resultados: Uma diferença média de aproximadamente uma hora ( $D P=2,1 ;$ mediana $=0,5 ; \mathrm{p}<0,01)$ foi encontrada entre ambas as estratégias, a qual foi maior entre os meninos, com 1,9 horas ( $\mathrm{DP}=2,8$; mediana $=1,6 ; \mathrm{p}<0,05$ ), do que entre as meninas, 0,5 horas $(\mathrm{DP}=1,4 ;$ mediana $=0,3 ; \mathrm{p}=0,11)$. A avaliação gráfica mostrou resultados semelhantes, bem como o coeficiente de correlação intraclasse: 0,06 (IC95\% $=-0,33-0,46 ; p=0,489$ ) para os meninos e $0,43($ IC $95 \%=0,12-0,83 ; p<0,001$ ) para as meninas. Conclusões: Nossos dados são consistentes com prévios estudos em relação à não concordância entre os dois métodos. Esses resultados são relevantes porque este é o primeiro estudo de concordância entre medidas subjetivas de sono e actigrafia em adolescentes brasileiros, do nosso conhecimento. Além disso, eles reforçam a necessidade de um cuidadoso uso das medidas de sono noturno entre adolescentes, principalmente entre os meninos.

Palavras-chave: Sono. Questionários. Actigrafia. Adolescentes. Gênero. Brasil.

\section{INTRODUCTION}

Adolescence is characterized by profound changes, which are typical of puberty, involving weight and height growth, psychosocial development, metabolism in general, and sleep ${ }^{1-3}$. Throughout this period, there is a tendency to decreased total sleep time, which in turn is a result from the delay in the onset of nocturnal sleep and early morning school beginning times, in addition to the non-recovery from sleep deprivation during the weekend ${ }^{1,4}$. Nowadays, the relation of sleep to various disorders has been acknowledged, including metabolic disorders ${ }^{5-7}$. Hence, the study of sleep regarding this age group is very pertinent.

Sleep can be evaluated through both subjective and objective methods. Polysomnography (PSG), a graphical record of brainwaves, ascertaining the various stages of sleep stands as the gold standard ${ }^{8}$. Sleep diaries, laboratory procedures, questionnaires, and interviews may also be used. On the last few decades, motion sensors have been developed to determine periods of activity and rest - a technique known as actigraphy $(\text { ACT })^{9}$, which was validated using PSG ${ }^{10,11}$.

In 2003, the American Academy of Sleep Medicine, through the Standards of Practice Committee (AASM / SPC), set parameters for the role of ACT in the study of sleep and circadian rhythms, establishing it as a valid and reliable measure for healthy and normal adults ${ }^{12}$. In 2007, the same institution published new parameters. This particular issue reported that the correlation between ACT and PSG was greater than that detected between the former and sleep diaries ${ }^{13}$.

Actigraphs are regarded as a more natural, noninvasive and practical alternative compared to $\mathrm{PSG}^{14}$, with also lower costs. They must be complemented by sleep diaries ${ }^{10,15}$ filled by parents, guardians or investigated individuals, and are more accurate than reports of interviews and/or questionnaires, if the latter are used alone $e^{10,11,16}$. 
Although with some limitations due to the dependence on memory, questionnaires and interviews have been used as tools in both qualitative and quantitative studies on sleep ${ }^{10,11,17-21}$, specifically for the feasibility in population studies.

This research aimed at assessing the agreement between specific questions about sleep and ACT in adolescents, studying the gender differences and, using a new graphical approach, the survival-agreement plot.

\section{MATERIALS AND METHODS}

This study is a preliminary stage of a research on the association of sleep duration with glucose metabolism ${ }^{2,5-7,22}$, which is part of a larger investigation called "Estudo de Riscos Cardiovasculares em Adolescentes" "Study of Cardiovascular Risks in Adolescents" - ERICA]. The latter is a multicenter study with 85,000 adolescents ranging from 12 to 17 years old, who attend public and private schools in 124 Brazilian cities with population over 100,000 inhabitants. The participants answered a questionnaire through an electronic data collector called "Personal Digital Assistant". The ERICA Questionnaire for Adolescents (EQA) includes a segment with specific questions about sleep duration.

\section{STUDY SAMPLE}

The research was carried out at the Instituto de Puericultura e Pediatria Martagão Gesteira of the Universidade Federal do Rio de Janeiro (IPPMG/UFRJ), in its pediatric clinic, from May to October 2012. The sample was comprised of 40 adolescents, aged 12 to 17 years. In order to define this sample size, WinPepi (School of Public Health and Community Medicine, Hebrew University, Jerusalem, Israel), version 11.22, was used for an expected intraclass correlation coefficient (ICC) of 0.85 , confidence interval length of 0.20 , a significance level of $0.05,10 \%$ losses and two observations per individual (one through the questionnaire and the other through the ACT).

During the study period, 77 young subjects were assisted in the pediatric clinic. However, 10 were excluded due to conditions of low cognition, chronic diseases, and/or use of drugs that could influence the records. In addition, 17 could not be contacted due to incorrect and/ or incomplete address / phone data. Considering the 50 adolescents available for selection, $10(20 \%)$ declined the invitation to participate, due to the parents and/or guardians' lack of available time for the research activities and procedures. There was a loss of three ACT data sets from three adolescents, resulting in a final sample of 37 individuals.

\section{STUDY PROCEDURES}

The sample has been described according to gender, age, education, nutritional status, and pubertal staging by self-assessment, according to illustrations of the Tanner scale. 
The weight and height of adolescents were obtained using a digital Filizzola ${ }^{\circledR}$ scale with a coupled stadiometer ( 2.5 to $150 \mathrm{~kg}$ of weight and height from 0 to $220 \mathrm{~cm}$ ).

The assessed sleep variables were the informed night sleep length in hours on the EQA (EQAs) and the duration of nocturnal sleep recorded by actigraphy (ACTs), both in the total sample and divided by gender.

The EQAs were determined based on the answers to the following questions: "On a typical week day, at what time do you usually sleep?"; "On a typical week day, at what time do you usually wake up?"; "On weekends, at what time do you usually sleep?" and "On weekends, at what time do you usually wake up?”. The weighted arithmetic mean of informed hours/minutes of sleep on weekdays and weekends was used for the evaluation of hours/minutes of nighttime sleep.

The Basic Mini Motionlogger Actigraph ${ }^{\circledR}$ (Ambulatory Monitoring, Inc.) was applied. The ACT was performed in the natural environment of the participants, 24 hours per day, during seven days. The device was placed on the non-dominant wrist, and should only be removed if there was risk of getting wet or being damaged. All adolescents were informed about the ACT positioning and the recording of events in an activity journal (sleep diary), in which an X should mark their occurrence (such as work, transport, study, physical activity, housework, TV/computer, sleep/naps, and device removal), every 24 hours, throughout the seven days of the study.

The "Zero Crossing Mode", ${ }^{, 23}$ was used for detection and recording data. Sadeh algorithm ${ }^{24}$ evaluated the sleep time, through the $A W 2^{\circledR}$ software (Ambulatory Monitoring Inc., 2000) with a sensitivity level greater than 40 to determine the epoch (60-second interval) as wakefulness.

For ACTs, sleep onset was established as the first minute of at least three consecutive minutes of sleep as scored by Sadeh algorithm. Similarly, the end of sleep was determined as the final one of the last five consecutive minutes of sleep as scored by the same algorithm ${ }^{25}$. The evaluation of hours / minutes of nighttime sleep through this method considered the mean of sleep period recorded for seven consecutive days, but measures of individuals with at least six days of registration, including at least one weekend day, were also taken into consideration.

Standardized procedures were adopted to ensure the quality of information to be obtained by the two methods. Furthermore, the ACT data editing was conducted by a single person, who was trained by a specialist.

\section{STATISTICAL ANALYSIS}

The average, median, and standard deviation for the numeric variables and the relative frequency (\%) for the categorical ones were applied to describe the study group. The initial performance approach of the EQA questions measuring the nocturnal sleep duration was done through the comparison of mean and median values obtained by the two instruments, through Wilcoxon signed-rank test. The agreement between the two strategies was determined by the ICC $^{26}$, Bland-Altman ${ }^{26,27}$ and survival-agreement plots ${ }^{26,28}$. The latter is based on the analogy with the survival analysis, using Kaplan-Meier survival curve. Aside from being able to assess the concordance among several methods simultaneously, it also establishes tolerance limits according to clinical relevance. The difference modulus between the methods is placed on the X-axis, while 
the mismatch percentage — calculated from the number of cases with module-observed differences - is indicated on the Y-axis. The concordance supported by the clinical relevance limits of this approach outweighs the presence of biases. Statistical significance was considered at $\mathrm{p}<0.05$ for all tests. The SPSS version 13 and the Stata version 9 were used.

The Ethics Committee of IPPMG/UFRJ, in accordance with the Declaration of Helsinki, approved this study. Parents or guardians signed an informed consent form, while the adolescents signed a statement of consent for participation in the study.

\section{RESULTS}

The age of participants ranged from 12 to 17 years (mean $=13.2, \mathrm{SD}=1.5$ ), with $35.1 \%$ being male. Overweight was observed in $27 \%$ of the adolescents and obesity in $13.5 \%$, according to the World Health Organization criteria. $70.2 \%$ of the whole group were in Tanner stages III or IV. About $92 \%$ of the subjects showed at least five years of study, all of them being enrolled and regularly attending school at the time of the research. The gender difference was not significant with respect to these variables.

Regarding sleep specifically, a significant difference of 1 hour on average $(\mathrm{SD}=2.1$; median $=$ $0.5 ; \mathrm{p}<0.01$ ) was observed between the two methods. When stratified by gender, the difference remained significant only for boys, with mean of 1.9 hours $(S D=2.8$; median $=1.6 ; \mathrm{p}<0.05)$. Among girls, the difference found was of 0.5 hours $(S D=1.4 ;$ median $=0.3 ; \mathrm{p}=0.11)$. Table 1 presents the summarized results in both total and gender-stratified samples, regarding EQAs and ACTs variables, and the difference between the two methods (EQAs - ACTs).

The Bland-Altman plot (Figure 1) also reflects the discrepancy between the methods, especially for males. The horizontal lines indicate the means for boys and girls, while the diagonal ones represent adjusted lines for both groups separately, showing a correlation greater than zero for both. Thus, with the presence of fixed and proportional biases, it is impossible to verify the concordance limits of \pm 1.96 SD compared to the averages of differences; therefore, they were not shown in Figure 1.

The survival-agreement plot shown in Figure 2 presents the same discrepancy. For a discordance of $20 \%$, or complementarily, a concordance of $80 \%$, girls differ in the

Table 1. Mean and median values of informed sleep duration, recorded sleep length by actigraphy, and the difference between the methods in both total and gender-stratified samples, in hours.

\begin{tabular}{l|c|c|c|c|c|c|}
\multirow{2}{*}{ Method } & \multicolumn{2}{|c|}{ Boys } & \multicolumn{2}{c|}{ Girls } & \multicolumn{2}{c}{ Total } \\
\cline { 2 - 7 } & Median & $\begin{array}{c}\text { Mean (SD) } \\
\mathrm{n}=13\end{array}$ & Median & $\begin{array}{c}\text { Mean (SD) } \\
\mathrm{n}=24\end{array}$ & Median & $\begin{array}{c}\text { Mean (SD) } \\
\mathrm{n}=37\end{array}$ \\
\hline EQAs $^{\dagger}$ & 10.0 & $9.9(2.7)$ & 8.4 & $8.6(1.7)$ & 8.7 & $9.1(2.2)$ \\
\hline ACTs $^{\ddagger}$ & 8.3 & $8.0(0.6)$ & 8.2 & $8.1(0.8)$ & 8.2 & $8.1(0.7)$ \\
\hline EQAs-ACTs & 1.6 & $1.9(2.8)^{*}$ & 0.3 & $0.5(1.4)$ & 0.5 & $1.0(2.1)^{* *}$
\end{tabular}

†EQAs: sleep assessed by the adolescent's questionnaire; ${ }^{\ddagger} A C T s$ : sleep assessed by actigraphy; ${ }^{\star} p<0.05$; ${ }^{* *} p<0.01$. 


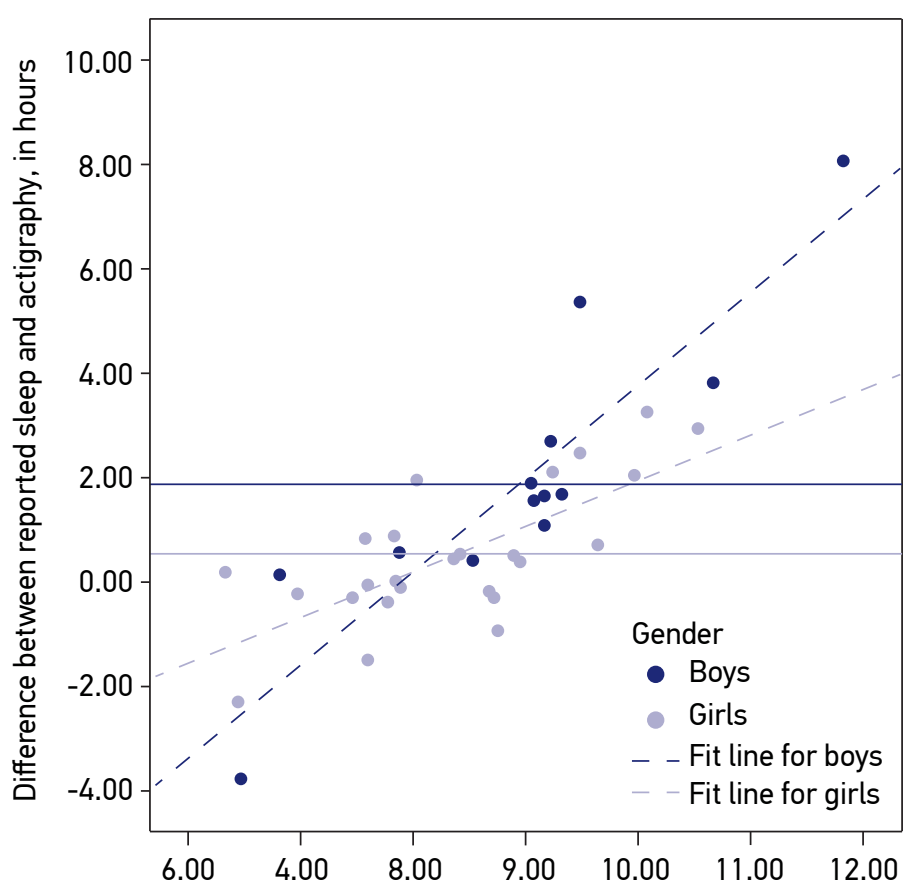

Mean between reported sleep and actigraphy, in hours

Figure 1. Bland-Altman plot by gender.

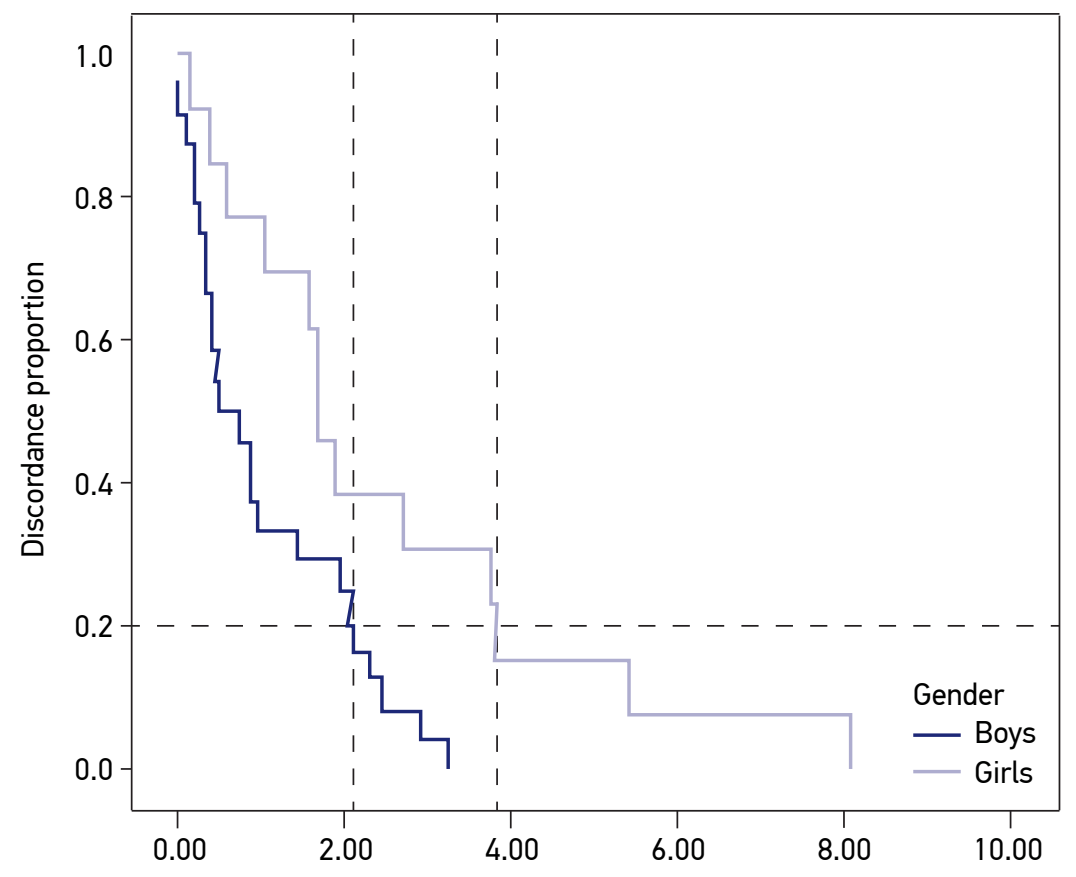

Modulus of the differences between reported sleep and actigraphy, in hours

Figure 2. Survival-agreement plot by gender. 
two methods in about two hours. For boys, the difference is around four hours for the same disagreement level.

Finally, the same pattern was found for the ICC: low for boys $(0.06 ; 95 \% \mathrm{CI}=-0.33-0.46$; $\mathrm{p}=0.49)$ and regular for girls $(0.43 ; 95 \% \mathrm{CI}=0.12-0.83 ; \mathrm{p}<0.05)$.

\section{DISCUSSION}

This study investigated the agreement between nocturnal sleep duration reported by adolescents and their nighttime sleep length recorded by ACT, analyzing the gender-related differences.

Similarly to previous reports ${ }^{15,19-21,29}$, this study found a discrepancy of about one hour on average (with SD of around two hours) between the informed sleep duration and the one measured objectively through ACT. While Lauderdale et al. ${ }^{19}$ studied young adults and Tomita et al. ${ }^{15}$ did the same with restless adults, the other three studies ${ }^{20,21,29}$ involved children and adolescents with ages ranging from 11 to 18 years, and all of them ascertained overestimation of subjective measures of sleep time when compared to the ACT. Tremaine, Dorrian and Blunden ${ }^{20}$ observed a difference of about one hour (66 minutes among adolescents and 72 minutes among children) in a group of 66 boys and girls ranging from 11 to 17 years, without gender-based differences, when comparing the sleep diaries with ACT. Working with 225 adolescents with age varying from 11 to 13 years, Arora et al. ${ }^{21}$ found an even greater discrepancy between the sleep time reported on the "School Sleep Habits Survey" and ACT, about one hour and 50 minutes on average, without discriminating gender-related differences. Short et al. ${ }^{29}$, however, provided a difference of one hour and 25 minutes between the measurements registered in the sleep diary and the ACT, as well a two-hour difference between the sleep duration related by parents and the objective one. These data were achieved by applying several subjective instruments, including the "School Sleep Habits Survey, the "Pediatric Daytime Sleepiness Scale" and the "Flinders Fatigue Scale", among 385 adolescents, with ages ranging from 13 to 18 years. This last investigation also examined measures of sleep regarding gender, and observed a greater discrepancy for boys (one hour and 46 minutes) against the 55 minutes seen for girls, between sleep diaries and ACT measures.

Regarding the graphical approaches applied to determine the acceptance limits of the differences, the works of Tremaine, Dorrian and Blunden ${ }^{20}$ and Arora et al. ${ }^{21}$, which used the Bland-Altman plots, showed results consistent with the differences reported and previously summarized. In Arora et al. ${ }^{21}$ study, the limits comprised a wide range of values for the differences (-22.84 - 276.43 minutes). Graphical differentiation by gender was not shown, however. Our research also provided correspondence between the mean differences of methods and results found in the graphs: the Bland-Altman and survival-agreement plots. If a lower concordance (70\%) is adopted for the survival-agreement graph analysis, the difference between subjective and objective measures decreases to about one hour and 30 minutes and two hours and 45 minutes, for the female and male groups, respectively. 
As shown, our data are consistent with previous studies regarding non-agreement between the two methods, with greater discrepancy among boys. These findings can be explained not only by the limitations of the subjective sleep reports, such as memory and interpretation of the mere act of going to bed as the sleep onset, overestimating it, but also by the ACT limitations - moments of restless sleep may be interpreted as wakefulness, underestimating the measured sleep duration ${ }^{9,21,29}$. According to this, boys can go to bed and still stay active longer than girls, before they really fall asleep.

Our study has some limitations. First, the sample size, although calculated, may have been insufficient for the gender-based study. Second, it was hospital-based, but selected from a group of healthy children or with mild pathologies that represented no hindrance to the study at the time of the data collection. Third, 10 adolescents declined to participate among the 50 available ones and, additionally, there was a $7 \%$ loss of ACT data sets referring to two boys and one girl. There is no reason to believe, however, that those, whose data were lost, would differ from the participants in the sample, in terms of sociodemographic characteristics. All the evaluated adolescents came from nearby communities to the clinic where the study was carried out, characterized by low socioeconomic status. Most of the subjects were enrolled in public schools.

\section{CONCLUSION}

Although expected, these results are relevant because this is probably the first study of concordance between subjective measures of sleep and ACT among Brazilian adolescents. In addition, such information reinforces the need of a careful use of nocturnal sleep measures among adolescents, mainly boys, using a new graphical approach to the study of the theme.

\section{ACKNOWLEDGEMENTS}

To the parents and adolescents who have accepted the invitation to collaborate with this work; Roberta Castro Rothstein, who assisted in the data collection and Cosme C. Pereira and the staff of the IPPMG/UFRJ for the administrative support.

\section{REFERENCES}

1. Carskadon M. Adolescent sleep patterns. Biological, social, and psychological influences. 2. ed. Cambridge: Cambridge University Press; 2004. 297p.

2. Kelly LA, Lane CJ, Weigensberg MJ, Toledo-Corral $\mathrm{CM}$, Goran MI. Pubertal changes of insulin sensitivity, acute insulin response, and $\beta$-cell function in overweight Latino youth. J Pediatr 2011; 158(3): 442-6.
3. Fischer FM, Radosevic-Vidacek B, Koscec A, Teixeira LR, Moreno CR, Lowden A. Internal and external time conflicts in adolescents: sleep characteristics and interventions. Mind Brain Educ 2008; 2(1): 17-23.

4. Tarokh L, Raffray T, Van Reen E, Carskadon MA. Physiology of normal sleep in adolescents. Adolesc Med State Art Rev 2010; 21(3): 401-17. 
5. Trento M, Broglio F, Riganti F, Basile M, Borgo E, Kucich C, et al. Sleep abnormalities in type 2 diabetes may be associated with glycemic control. Acta Diabetol 2008; 45(4): 225-9.

6. Spruyt K, Molfese DL, Gozal D. Sleep duration, sleep regularity, body weight, and metabolic homeostasis in school-aged children. Pediatrics 2011; 127(2): e345-52.

7. Landis AM, Parker KP. A retrospective examination of the relationship between body mass index and polysomnographic measures of sleep in adolescents. J Adolesc Health 2007; 40(1): 89-91.

8. Toth LA, Jhaveri K. Sleep mechanisms in health and disease. Comp Med 2003; 53(5): 473-86.

9. Sadeh A, Acebo C. The role of actigraphy in sleep medicine. Sleep Med Rev 2002; 6(2): 113-24.

10. Kushida CA, Chang A, Gadkary C, Guilleminault C, Carrillo O, Dement WC. Comparison of actigraphic, polysomnographic, and subjective assessment of sleep parameters in sleep-disordered patients. Sleep Med 2001; 2(5): 389-96.

11. Gregory AM, Cousins JC, Forbes EE, Trubnick L, Ryan ND, Axelson DA, et al. Sleep items in the child behavior checklist: a comparison with sleep diaries, actigraphy, and polysomnography. J Am Acad Child Adolesc Psychiatry 2011; 50(5): 499-507.

12. Littner M, Kushida CA, Anderson WM, Bailey D, Berry RB, Davila DG, et al. Practice parameters for the role of actigraphy in the study of sleep and circadian rhythms: an update for 2002. Sleep 2003; 26(3): 337-41.

13. Morgenthaler T, Alessi C, Friedman L, Owens J, Kapur $\mathrm{V}$, Boehlecke B, et al. Practice parameters for the use of actigraphy in the assessment of sleep and sleep disorders: an update for 2007. Sleep 2007; 30(4): 519-29.

14. Lockley SW, Skene DJ, Arendt J. Comparison between subjective and actigraphic measurement of sleep and sleep rhythms. J Sleep Res 1999; 8(3): 175-83.

15. Tomita S, Kitajima T, Mekata T, Tsuchiya A, Sano W, Esaki Y, et al. Comparison of sleep diary and actigraphy to evaluate total sleep time in hypersomnia patients. Sleep Biol Rhythms 2013; 11: 65-73.

16. Weiss AR, Johnson NL, Berger NA, Redline S. Validity of activity-based devices to estimate sleep. J Clin Sleep Med 2010; 6(4): 336-42.

17. Werner H, Molinari L, Guyer C, Jenni OG. Agreement rates between actigraphy, diary, and questionnaire for children's sleep patterns. Arch Pediatr Adolesc Med 2008; 162(4): 350-8.
18. Gaina A, Sekine M, Chen X, Hamanishi S, Kagamimori S. Validity of child sleep diary questionnaire among junior high school children. J Epidemiol 2004; 14(1): 1-4.

19. Lauderdale DS, Knutson KL, Yan LL, Liu K, Rathouz PJ. Self-reported and measured sleep duration: how similar are they? Epidemiology 2008; 19(6): 838-45.

20. Tremaine RB, Dorrian J, Blunden S. Subjective and objective sleep in children and adolescents: Measurement, age, and gender differences. Sleep Biol Rhythms 2010; 8: 229-38.

21. Arora T, Broglia E, Pushpakumar D, Lodhi T, Taheri $S$. An investigation into the strength of the association and agreement levels between subjective and objective sleep duration in adolescents. PLoS One 2013; 8(8): e72406.

22. Tamborlane WV. Diabetes in overweight pediatric patients. Clin Cornerstone 2005; 7 Suppl 3: S25-9.

23. Johnson NL, Kirchner HL, Rosen CL, Storfer-Isser A, Cartar LN, Ancoli-Israel S, et al. Sleep estimation using wrist actigraphy in adolescents with and without sleep disordered breathing: a comparison of three data modes. Sleep 2007; 30(7): 899-905.

24. Sadeh A, Sharkey KM, Carskadon MA. Activity-based sleep-wake identification: an empirical test of methodological issues. Sleep 1994; 17(3): 201-7.

25. Wolfson AR, Carskadon MA, Acebo C, Seifer R, Fallone G, Labyak SE, et al. Evidence for the validity of a sleep habits survey for adolescents. Sleep 2003; 26(2): 213-6.

26. Luiz RR. Métodos estatísticos em estudos de concordância. Epidemiologia. 2. ed. São Paulo: Atheneu; 2008. 790p.

27. Bland JM, Altman DG. Statistical methods for assessing agreement between two methods of clinical measurement. Lancet 1986; 1(8476): 307-10.

28. Luiz RR, Costa AJ, Kale PL, Werneck GL. Assessment of agreement of a quantitative variable: a new graphical approach. J Clin Epidemiol 2003; 56(10): 963-7.

29. Short MA, Gradisar M, Lack LC, Wright H, Carskadon MA. The discrepancy between actigraphic and sleep diary measures of sleep in adolescents. Sleep Med 2012; 13(4): 378-84.

Received on: 10/01/2014

Final version presented on: 08/25/2015

Accepted on: 09/15/2015 